\title{
FIRST RECORD OF IXODES ARIADNAE IN WESTERN EUROPE, BELGIUM - SHORT COMMUNICATION
}

\author{
Sándor HORNOK ${ }^{1 *}$ and Aleksandra KRAWCZYK ${ }^{2}$ \\ ${ }^{1}$ Department of Parasitology and Zoology, University of Veterinary Medicine, István u. 2, \\ H-1078 Budapest, Hungary; ${ }^{2}$ Centre for Infectious Disease Control, National Institute \\ for Public Health and the Environment (RIVM), Bilthoven, The Netherlands
}

(Received 14 June 2016; accepted 2 November 2016)

\begin{abstract}
Fourteen long-legged ixodid ticks (6 nymphs and 8 larvae) were collected from Bechstein's bat (Myotis bechsteinii) in Rochefort, Belgium. All ticks were morphologically identified as Ixodes ariadnae, based on their long legs (Haller's organ longer than maximum diameter of tarsus I), broad palps and posteriorly reverse bell-shaped scutum with wavy surface. The DNA was extracted from these ticks, followed by PCR amplification of part of their cytochrome oxidase subunit I (COI) gene. All obtained sequences were $100 \%$ identical with each other, and with the COI sequence of I. ariadnae reported previously from Hungary and Germany. Taking into account that the collection site in the present study is close to the French border of Belgium, and migration of Bechstein's bat is known between Belgium and France, it is reasonable to suppose that I. ariadnae also occurs in France. This is the first record of I. ariadnae in Western Europe, outside its formerly known geographical range (Central Europe).
\end{abstract}

Key words: Bat, hard tick, Ixodes, Myotis bechsteinii

Bats form the second largest order (Chiroptera) of mammals. Their epidemiological significance has become increasingly recognised, owing to their flight ability, migratory habit and presence in the urban environment, where they may use man-made buildings (houses, cellars, churches, stables) for roosting (Hutterer et al., 2005). In addition, numerous bat species and their blood-sucking ectoparasites have been identified as carriers of important pathogens to which humans and/or domestic animals are susceptible (Socolovschi et al., 2012). Feeding of bat ectoparasites (particularly of ticks) on humans (Jaenson et al., 1994; Piksa et al., 2013) may represent an opportunity for zoonotic pathogen transmission.

Ixodes ariadnae is a recently described hard tick species of bats (Hornok et al., 2014). Hitherto it has been reported from two Central European countries, Hungary and Germany (Hornok et al., 2015a). However, long-legged bat ticks

${ }^{*}$ Corresponding author; E-mail: Hornok.Sandor@univet.hu; Phone: 0036 (1) 478-4187, Fax: 0036 (1) 478-4193 
morphologically and genetically most similar to $I$. ariadnae are geographically more widespread, and have already been reported from southern and eastern Asia (Hornok et al., 2015b).

The preferred hosts of I. ariadnae are Myotis spp. and Plecotus auritus (Chiroptera: Vespertilionidae) (Hornok et al., 2014, 2015a,b). The genus Myotis is represented by the highest number of (i.e. sixteen) bat species in Europe, and at least half of them occur in the western part of our continent (Hutterer et al., 2005). Taking also into account that some Myotis spp. are able to migrate (relatively) long distances, it is justifiable to suppose that $I$. ariadnae should be present (but was hitherto unknown to occur) in Western Europe. Here we report the morphological and molecular identification of long-legged bat ticks collected in Belgium.

In September of 2013 and 2015, fourteen long-legged ixodid ticks (6 nymphs and 8 larvae) were collected from Bechstein's bat (M. bechsteinii) in Grotte de Lorette (50.155N, 5.2281E), Namur Province, Rochefort, Belgium. This natural cave is a very important site for bats in the region, during both hibernation and swarming, with at least eleven bat species (Nyssen et al., 2015). The collection site is shown in Fig. 1. The authorisation number for bat handling was SPWDNFDGO3 (2013/RS/n ${ }^{\circ} 15$ and 2014/RS/n ${ }^{\circ} 12$, issued in Belgium).

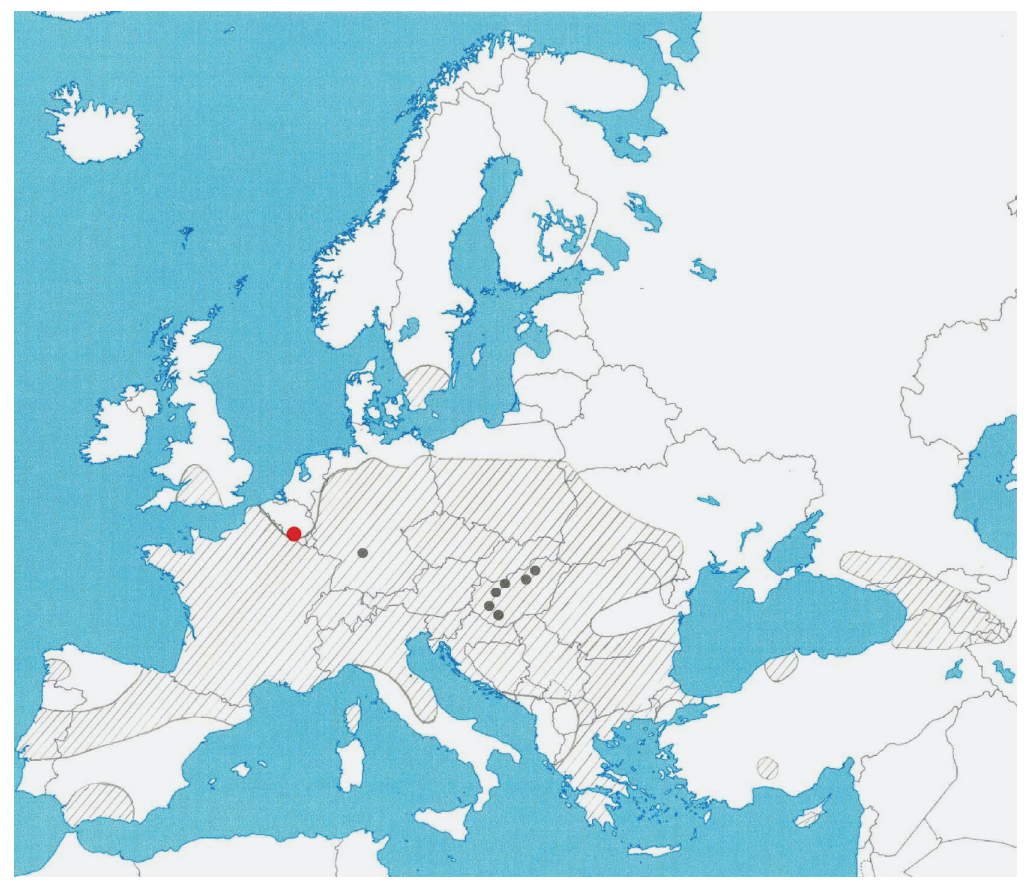

Fig. 1. Map of Europe showing the collection site of I. ariadnae in Belgium in the present study (red dot) and previously known occurrence of this tick species in Germany and Hungary (black dots). The shaded area marks the distribution range of Myotis bechsteinii 
The ticks were stored in $96 \%$ ethanol. Morphological identification was based on the description of I. ariadnae (Hornok et al., 2014, 2016). Pictures of representative specimens were taken with a digital microscope (Zeiss Stereo Discovery microscope LZO 0191 with AxioCam ICc5 camera and ZEN software). Consequently, DNA was extracted from the ticks individually using the Qiagen DNeasy Blood \& Tissue Kit according to the manufacturer's protocol for the purification of total DNA from ticks (Qiagen, Venlo, The Netherlands).

The cytochrome oxidase subunit I (COI) gene was chosen for confirmation and genetic comparison of the species, because this gene is regarded as the most suitable marker for molecular identification (barcoding) of tick species ( $\mathrm{Lv}$ et al., 2014). The PCR was modified from Folmer et al. (1994) and amplifies an approx. 710-bp-long fragment of the gene. The PCR was performed with the HotStarTaq master mix (Qiagen, Venlo, The Netherlands) and primers HCO2198 (5'-TAA ACT TCA GGG TGA CCA AAA AAT CA-3') and LCO1490 (5'-GGT CAA CAA ATC ATA AAG ATA TTG G-3'). For amplification, an initial denaturation step at $95^{\circ} \mathrm{C}$ for 15 min was followed by 40 cycles of denaturation at $94{ }^{\circ} \mathrm{C}$ for $30 \mathrm{~s}$, annealing at $48{ }^{\circ} \mathrm{C}$ for $40 \mathrm{~s}$ and extension at $72{ }^{\circ} \mathrm{C}$ for $50 \mathrm{~s}$. Final extension was performed at $72{ }^{\circ} \mathrm{C}$ for $10 \mathrm{~min}$.

PCR products were visualised in a $1.5 \%$ agarose gel. Sequencing was performed with Sanger method BaseClear (BV BaseClear, Leiden, The Netherlands) and sequences were compared by nucleotide BLASTN program (https://blast. ncbi.nlm.nih.gov). One representative sequence was submitted to GenBank (accession number: KX375410).

All ticks were morphologically identified as I. ariadnae. This diagnosis is based on the presence of long legs (i.e. Haller's organ elongated, longer than the maximum diameter of tarsus I), like in the case of I. vespertilionis. However, specimens investigated in the present study had laterally straight and medially curved palps (Fig. 2), broader than those of $I$. vespertilionis. In addition, the scutum was posteriorly reverse bell-shaped, with wavy surface (Fig. 2), unlike in the case of I. vespertilionis (Arthur, 1956).

All obtained COI sequences were $100 \%$ identical with each other and with the COI sequence of $I$. ariadnae reported formerly from Hungary (KJ490306) and Germany (KR093169). Accordingly, while I. vespertilionis was shown to have different COI genotypes within Hungary (most likely due to the sedentary habit and limited seasonal movements of its main host, Rhinolophus hipposideros: Hutterer et al., 2005), I. ariadnae appears to show highly conserved COI sequences over large geographical distances, as demonstrated here. This can be explained by longer distance movements of Myotis spp. (the preferred hosts of I. ariadnae) in Europe (Hutterer et al., 2005). In particular, M. bechsteinii, from which all specimens of this study were collected (i.e. it appears to be an important host of I. ariadnae), is known to have a social system and roosting behaviour 
allowing transmission of ectoparasites and their genetic exchange between different bat colonies (van Schaik et al., 2015).

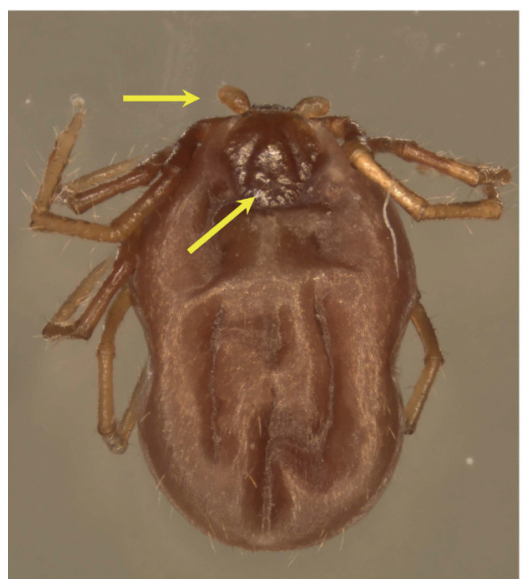

nymph: dorsal

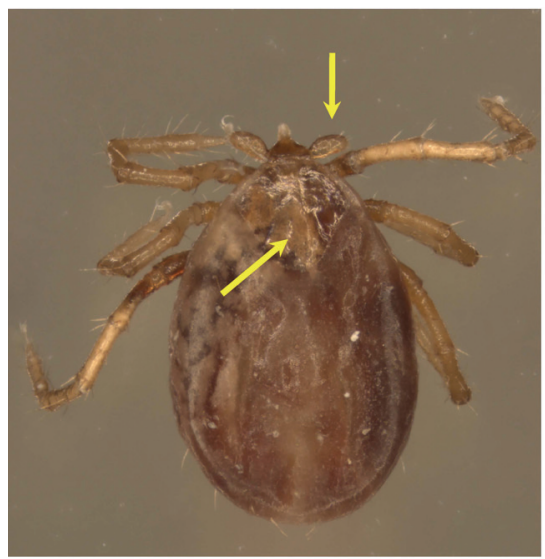

larva: dorsal

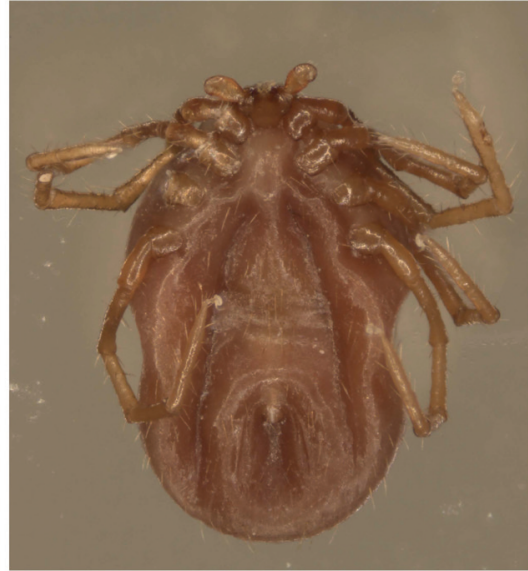

nymph: ventral

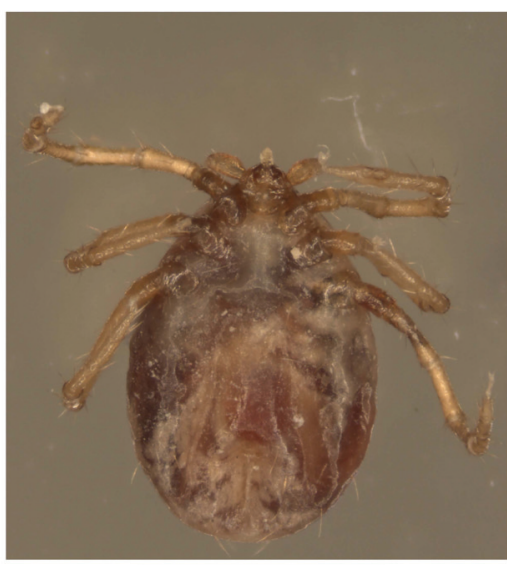

larva: ventral

Fig. 2. Dorsal and ventral views of I. ariadnae nymph and larva collected in the present study. Arrows indicate species characteristics (broad palps curved medially but straight laterally; wavy surface of scutum in its reverse bell-shaped, posterior part)

This is the first record of I. ariadnae in Western Europe, outside its formerly known geographical range (Central Europe). Taking into account that the collection site in the present study is close to the French border of Belgium, and migration of Bechstein's bat is known between Belgium and France (Hutterer et al., 2005), it is reasonable to suppose that I. ariadnae also occurs (at least on this bat species) in France. Therefore, it is suggested to extend tick collections from 
Myotis spp. to other countries in Western Europe, in order to uncover the full geographical range of $I$. ariadnae in the region.

\section{Acknowledgements}

The authors are grateful to Daan Dekeukeleire and Quentin Smits for collecting the samples, for performing morphological identification of ticks and for proposing barcoding. Furthermore, authors would like to thank Manoj Fonville for providing pictures of specimens. This research was supported by the 11475-4/2016/FEKUT grant of the Hungarian Ministry of Human Resources. Colour printing was supported by OTKA 115854.

\section{References}

Arthur, D. R. (1956): The Ixodes ticks of Chiroptera (Ixodoidea, Ixodidae). J. Parasitol. 42, 180-196.

Folmer, O., Black, M., Hoeh, W., Lutz, R. and Vrijenhoek, R. (1994): DNA primers for amplification of mitochondrial cytochrome $\mathrm{C}$ oxidase subunit I from diverse metazoan invertebrates. Mel. Marine. Biol. Biot. 3, 294-299.

Hornok, S., Kontschán, J., Kováts, D., Kovács, R., Angyal, D., Görföl, T., Polacsek, Z., Kalmár, Z. and Mihalca, A. D. (2014): Bat ticks revisited: Ixodes ariadnae sp. nov. and allopatric genotypes of $I$. vespertilionis in caves of Hungary. Parasit. Vectors 7, 202.

Hornok, S., Takács, N., Szőke, K. and Kunz, B. (2015a): First record of Ixodes ariadnae in Germany. Acta Vet. Hung. 63, 347-351.

Hornok, S., Estrada-Peña, A., Kontschán, J., Plantard, O., Kunz, B., Mihalca, A. D., Thabah, A., Tomanović, S., Burazerović, J., Takács, N., Görföl, T., Estók, P., Tu, V. T., Szőke, K., Fernández de Mera, I. G., de la Fuente, J., Takahashi, M., Yamauchi, T. and Takano, A. (2015b): High degree of mitochondrial gene heterogeneity in the bat tick species Ixodes vespertilionis, I. ariadnae and I. simplex from Eurasia. Parasit. Vectors 8, 457.

Hornok, S., Kováts, D., Angyal, D., Dányi, L., Kovács, R. and Kontschán, J. (2016): Description of the male and the larva of Ixodes ariadnae Hornok, 2014. Ticks Tick Borne Dis. 7, 1252-1255.

Hutterer, R., Ivanova, T., Meyer-Cords, C. and Rodrigues, L. (2005): Bat Migrations in Europe. A Review of Banding Data and Literature. Naturschutz und BiologischeViefalt 28. Federal Agency for Nature Conservation, Bonn.

Jaenson, T. G., Tälleklint, L., Lundqvist, L., Olsen, B., Chirico, J. and Mejlon, H. (1994): Geographical distribution, host associations, and vector roles of ticks (Acari: Ixodidae, Argasidae) in Sweden. J. Med. Entomol. 31, 240-256.

Lv, J., Wu, S., Zhang, Y., Chen, Y., Feng, C., Yuan, X., Jia, G., Deng, J., Wang, C., Wang, Q., Mei, L. and Lin, X. (2014): Assessment of four DNA fragments (COI, 16S rDNA, ITS2, $12 \mathrm{~S}$ rDNA) for species identification of the Ixodida (Acari: Ixodida). Parasit. Vectors 7, 93.

Nyssen, P., Smits, Q., Van de Sijpe, M., Vandendriessche, B., Halfmaerten, D. and Dekeukeleire, D. (2015): First records of Myotis alcathoe von Helversen \& Heller, 2001 in Belgium. Belg. J. Zool. 145, 130-136.

Piksa, K., Nowak-Chmura, M. and Siuda, K. (2013): First case of human infestation by the tick Ixodes vespertilionis (Acari: Ixodidae). Int. J. Acarol. 38, 1-2.

Socolovschi, C., Kernif, T., Raoult, D. and Parola, P. (2012): Borrelia, Rickettsia, and Ehrlichia species in bat ticks, France, 2010. Emerg. Infect. Dis. 18, 1966-1975.

van Schaik, J., Dekeukeleire, D. and Kerth, G. (2015): Host and parasite life history interplay to yield divergent population genetic structures in two ectoparasites living on the same bat species. Mol. Ecol. 24, 2324-2335. 